\section{Project management educational curriculum for public health professionals: development and evaluation}

\author{
David M. Sabapathy,' David Strong, ${ }^{2}$ \\ Hude Quan ${ }^{3}$ \\ 'Department of Community Health \\ Sciences, University of Calgary, Alberta; \\ ${ }^{2}$ Medical Officer of Health, Alberta \\ Health Services, Calgary, Alberta; \\ ${ }^{3}$ Associate Professor, Department of \\ Community Health Sciences, University \\ of Calgary, Calgary, Alberta, Canada
}

\section{Abstract}

Successful completion of public health projects is critical to achieving population health objectives. However project execution can be challenging due to scarce time and resources, rapidly changing environments and complex stakeholder requirements. To address these challenges physicians and other professionals working in public health need to learn the practical skills of project management. However curricula tailored to project management skill development for public health professionals is not widely available. A one-week curriculum on project management for public health professionals has been developed enabling participants to independently lead small-scale public health projects. This course adapts a private-sector curriculum for use in public health practice and incorporates a unique skill-building teaching method. Evaluation of the initial curriculum delivery at the Weill-Bugando University, Tanzania indicated the majority of students intended to use project management upon return to their positions in public health. Students indicated a lack of a critical mass of public health professionals with required knowledge and skills represents the greatest barrier to integration of project management into public health practice. A unique one-week curriculum in project management has been developed and is being made publicly available. The course will enable physicians and other professionals working in public health to rapidly learn and apply the methodology to the front lines of public health.

\section{Introduction}

Projects are time-limited endeavors that produce unique outcomes distinct from an organization's day-to-day activities. ${ }^{1}$
Successful completion of public health projects is critical to achieving population health objectives. However project execution is often challenging due to scarce time and resources, rapidly changing environments and complex staeholder requirements. Project management is a process for planning and executing projects to accomplish desired outcomes given a set of environmental constraints such as limited time and resources. ${ }^{2}$ Project management addresses the challenges associated with public health projects by guiding them through the consecutive stages of initiation, definition, planning, execution and close-out. In the initiation stage an idea for a public health initiative is proposed and endorsed by leadership. The definition stage follows and describes the project scope and deliverables while the planning stage develops a work schedule and budget. Lastly the project is executed and evaluated during the close-out stage.

Though project management has a long history of successful use in private enterprise and international organizations such as the Project Management Institute ${ }^{3}$ support globally-recognized standards and professional development opportunities, the methodology has not been widely embraced by health professionals. Although the U.S. Centers for Disease Control and Prevention has developed an on-line project management guide for internal use $\mathrm{e}^{4}$ and one textbook provides an outline of project management for the community health sciences, ${ }^{5}$ academic and professional programs focused on project management for public health are not widely available.

Project management has significant potential to contribute to public health professional practice. Health needs assessments, health promotion and disease prevention initiatives, environmental health risk assessments and evidence-based research agendas are just some applications that would benefit from effective planning and implementation using project management principles. Medical students training to work in primary care or public health settings, especially in resource-constrained developing countries, can benefit from an introduction to project management during their medical education. Project management is an important skill set for improving the health of the communities these future physicians will serve and they may be called upon as leaders, decision-makers or consultants on public health projects.

However, existing private-sector curricula require re-focusing to ensure relevancy in public health practice. In addition, curriculum delivery must be tailored to maximize uptake by physicians and other public health professionals. To meet this need we discuss the development of an innovative one-week curriculum on project management for public health professionals enabling participants to
Correspondence: David M. Sabapathy, Department of Community Health Sciences, University of Calgary, 3280 Hospital Drive N.W., Calgary, Alberta, Canada T2N 4Z6

Tel. +1.403.771.0028 - Fax: +1.403.270.7307.

E-mail: david.sabapathy@albertahealthservices.ca

Funding: the Unversity of Calgary, Faculty of Medicine, Postgraduate Medical Education funded DMS travel to Tanzania.

Conflict of interest: the authors report no conflicts of interest.

Received for publication: 17 March 2011.

Revision received: 2 June 2011.

Accepted for publication: 3 June 2011.

This work is licensed under a Creative Commons Attribution NonCommercial 3.0 License (CC BYNC 3.0).

(C) Copyright D.M. Sabapathy et al., 2011

Licensee PAGEPress, Italy

Medical Education Development 2011; 1:e6

doi:10.4081/med.2011.e6

independently lead small-scale public health projects. The course is reviewed following its delivery to sixteen Master of Public Health students in an international health setting.

\section{Innovation}

In 2010, an 18-month Master of Public Health (MPH) program was initiated at the Weill-Bugando University College of Health Sciences (WBUCHS) in Mwanza, northwest Tanzania with teaching by local faculty and visiting lecturers from the Department of Community Health Sciences at the University of Calgary in Alberta, Canada. Sixteen students registered in the program which is targeted towards physicians and medical professionals working in senior public health administration in Tanzania. A one-week curriculum on project management fundamentals was developed to meet program needs.This curriculum was unique in its adaptation of private-sector curricula for use in public health practice and application of a skill-building integrated learning model.

The curriculum development process began with a broad review of existing literature. Though a wealth of private-sector project management material exists, each industry tailors the methodology to its unique needs. As a result there was significant variation in the steps, depth of detail and applicability of examples to public health practice. ${ }^{6-9}$ Curriculum development therefore drew on our collective experience in project management and public 
health practice to adapt and integrate industry materials for medical education. The project life cycle, a ubiquitous construct in project management, was used as a framework for the course and re-interpreted to emphasize stages of the cycle most critical to the success of public health projects (Figure 1).

The principal learning objective for the course was to acquire practical skills in project management' that could be directly translated to the students administrative positions. To achieve this objective a skill-building integrated learning model was developed (Figure 2) to emphasize hands-on learning of the methods and tools. Teams of 4 to 5 students selected projects based on a public health priority in their local community. Projects were completed using three activity modules which followed didactic teaching for corresponding stages of the project life cycle. Didactic concepts were illustrated using a fully-worked conventional case study on increasing measles immunization coverage in alignment with the Millennium Development Goals. ${ }^{10}$ Teams completed modules by mimicking the project management techniques demonstrated in the case example. To simulate interactions on a project team, participants completed the modules by assuming traditional project management roles and responsibilities: project manager, designer, administrator, client representative and implementer.

Completion of the activity modules at the end of Day 4 resulted in an actionable project management plan for each team. Final projects represented initiatives from environmental health, infection prevention and control, health promotion and communicable disease management. On Day 5 teams presented their projects in a role play simulating a project meeting for a key milestone: approval of the project plan. Plan integrity was probed by stakeholders represented by the instructor and student audience. Team members presented and responded to questions according to their unique role on the project management team. The course outline is presented in Table 1 and the detailed curriculum is available for public use at http://www.ucalgary.ca/cipph/projectmanagementcurriculum.

Two challenges arose during curriculum delivery. Students lacking computer knowledge took longer to complete the activity modules. This may be addressed by administering the curriculum solely as a paper-based course. Due to the complexity of the learning model for the course,students required occasional re-orientation to the course structure. In response, symbols representing the case example (lightbulb representing the measles immunization project idea), activity modules (pen and notepad) and project management plan (projector) were developed as useful guides throughout the materials.

\section{Evaluation}

By course end each team produced an actionable project management plan which was viable in a public health setting. We designed a questionnaire prior to administra- tion of the course to assess feedback following course delivery. Questionnaire results indicated the majority of students expected to use project management principles upon return to their positions in public health administration. The most encouraging comments from the post-course evaluation indicated some stu-

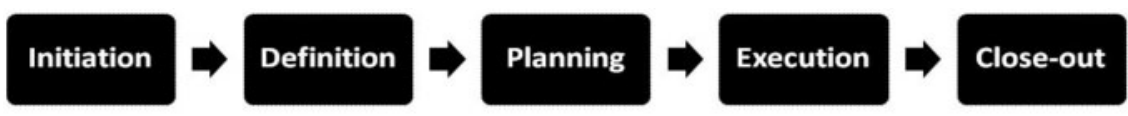

Figure 1. Project life cycle for public health initiatives.

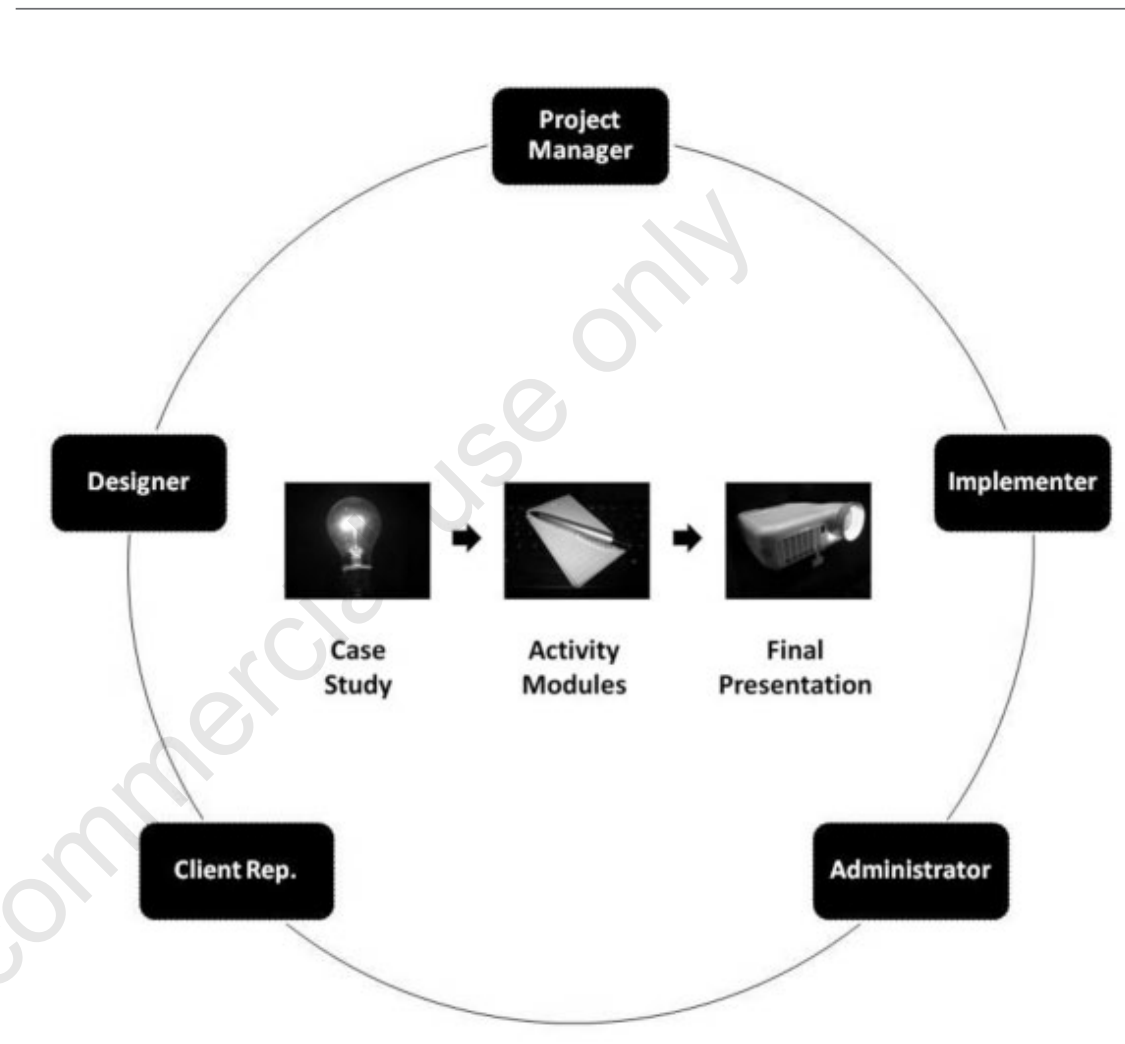

Figure 2. Skill-Building integrated learning model.

Table 1. Course outline.

\begin{tabular}{|c|c|c|}
\hline Schedule & Topic & Objectives \\
\hline \multirow[t]{4}{*}{ Day 1} & Introduction to & 1. Project management approach \\
\hline & project management & 2. Project life cycle \\
\hline & Project initiation & 3. Project idea and stakeholders \\
\hline & & - Teams form and identify project idea \\
\hline Day 2 & Project definition & $\begin{array}{l}\text { 4. Project charter } \\
\text { - Teams complete activity module \#1 }\end{array}$ \\
\hline Day 3 & Project definition & $\begin{array}{l}\text { 5. Project design, work breakdown, apportionment } \\
\text { - Teams complete activity module \#2 }\end{array}$ \\
\hline \multirow[t]{2}{*}{ Day 4} & & $\begin{array}{l}\text { 6. Scheduling, estimation, budgeting } \\
\text { - Teams complete activity module \#3 }\end{array}$ \\
\hline & Project execution and close-out & $\begin{array}{l}\text { 7. Execution and close-out } \\
\text { - Teams complete project management plans }\end{array}$ \\
\hline Day 5 & Course conclusion & 8. Team presentations and course evaluation \\
\hline
\end{tabular}


dents felt they could now initiate previously daunting public health initiatives using the structured project management methods as a starting point. The greatest perceived barrier to uptake of the methodology was achievement of a critical mass of public health professionals with knowledge and skills in project management facilitating a common approach to public health projects.

Future evaluation efforts will focus on qualitative and quantitative comparison of project management knowledge and skills pre and post course delivery. Since the principal learning objective for the course is to acquire practical skills in project management, the impact of the course may be further assessed by reviewing the successes and challenges encountered by teams in completing their projects upon return to their administrative positions.

\section{Conclusion}

Project management is an essential tool for the public health practitioner. Future physicians can benefit from an introduction to proj- ect management during their medical education as they may be called upon as leaders, decision-makers or consultants on public health projects. The one-week curriculum described here is an opportunity for current and future physicians as well as other medical professionals to rapidly learn the practical skills of project management for application to the front lines of public health. Modification of the material may be required to meet local needs.

\section{References}

1. Project Management Institute Inc. A Guide to the Project Management Body of Knowledge (PMBOK Guide). 3rd ed. Pennsylvania: Project Management Institute Inc 2004;5.

2. Chiu YC. An introduction to the History of Project Management From the Earliest Times to A.D.1900. Delft, Netherlands: Eburon Academic Publishers; 2010;1-5.

3. Project Management Institute Inc. About the Project Management Institute; 2010. Available from: http://www.pmi.org/About-
Us.aspx.

4. Centers for Disease Control and Prevention. CDC Unified Process; 2010. Available from: http:/www2.cdc.gov/ cdcup/.

5. Dwyer J, Stanton P, Thiessen V. Project Management in Health and Community Services: Getting good ideas to work. London: Routledge; 2004.

6. Schwalbe K. Introduction to Project Management. Boston: Thomson - Course Technology; 2006.

7. Kyle M. Making it Happen: A NonTechnical Guide to Project Management. Etobicoke: John Wiley \& Sons Canada, Ltd.; 1998.

8. Campbell CA. The One-Page Project Manager: Communicate and Manage Any Project with a Single Sheet of Paper. Hoboken, New Jersey: John Wiley \& Sons, Inc.; 2007.

9. Verzuh E. The Fast Forward MBA in Project Management. 3rd edition ed. Hoboken, New Jersey: John Wiley \& Sons; 2008.

10. United Nations. Millennium Development Goals Report; 2010. Available from: http:/www.un.org/millenniumgoals/pdf/M DG\%20Report\%202010\%20En\%20r15\%20low\%20res\%2020100615\%20-.pdf. 